\title{
Clinical Comparison of Epidural Clonidine and Verapamil with Ropivacaine in Abdominal Hysterectomy; A Prospective, Randomized, Controlled Study.
}

\author{
Suraj Kumar', Manoj Tripathi', Deepak Malviya ${ }^{2}$, Sujeet Rai ${ }^{3}$, Sumit Kumar', Manoj Kumar Giri ${ }^{3}$ \\ ${ }^{1}$ Assistant Professor, Department of Anaesthesia \& Critical Care, Dr. Ram Manohar Lohia Institute of Medical Sciences, Lucknow, Uttar Pradesh, India, \\ ${ }^{2}$ Professor \& Head, Department of Anaesthesia \& Critical Care, Dr. Ram Manohar Lohia Institute of Medical Sciences, Lucknow, Uttar Pradesh, India, \\ ${ }^{3}$ Associate Professor, Department of Anaesthesia \& Critical Care, Dr. Ram Manohar Lohia Institute of Medical Sciences, Lucknow, Uttar Pradesh, India.
}

\section{Abstract}

Background: Adjuvants, when combined with local anaesthetics, increase duration of block, improve quality of blockade and accelerate onset of block. The aim of this study is to assess the analgesic properties and postoperative analgesia of Clonidine and verapamil in the epidural block for abdominal hysterectomy. Subjects and Methods: Ninety patients were divided into three groups Group 1- patient were given ropivacaine $(0.75 \%)$ in the dose of $20 \mathrm{ml}$, Group II $-0.75 \%$ ropivacaine $20 \mathrm{ml}$ with verapamil in the dose of $2.5 \mathrm{ml}$, Group III $-0.75 \%$ ropivacaine $20 \mathrm{ml}$ with Clonidine in the dose of $1 \mathrm{mcg} / \mathrm{kg}$ body weight. Patients were assessed for onset, degree, level, duration of sensory and motor block, duration of complete analgesia and postoperative analgesia, rescue analgesic requirement, sedation score and adverse effects. Results: When groups I and II were compared, onset of sensory and motor block was found to be statistically insignificant ( $>0.05$ ), while it was early in group III in comparison to groups I and II and statistically significant $(\mathrm{p}<0.05)$. The duration of sensory block in group III was more in comparison to groups I and II and were statistically significant $(\mathrm{p}<0.05)$. The mean duration of analgesia in group I was $184.03+$ $5.20 \mathrm{mins}$, in group II was $300.46+5.80 \mathrm{mins}$ and in groups, III was $538+12.80$ mins. Conclusion: Verapamil does not enhance the onset, duration of the sensory and motor block, though Clonidine in the dose of $1 \mathrm{ug} / \mathrm{kg}$ enhances the onset of sensory block. The duration of postoperative analgesia with verapamil was more and much higher compared to Clonidine.

Keywords: Clonidine, epidural, ropivacaine, hysterectomy, analgesia.

Corresponding Author: Dr. Manoj Tripathi, MD PDCC, Department of Anaesthesia \& Critical Care, Dr. Ram Manohar Lohia Institute of Medical Sciences, Lucknow.

Email: georgian.manojt@gmail.com

Received: April 2020

Accepted: April 2020

\section{Introduction}

Epidural anesthesia is the most versatile \& suitable neuraxial technique of central neural blockade and provides excellent pain relief both intraoperatively \& postoperatively with a very low incidence of side effects. The main limitation of an epidural block is its slower onset of action, limited duration of action and requirement of high dose. Here comes the role of adjutants. These adjuvants, when combined with local anesthetics, increase the duration of block, improve the quality of blockade and accelerate onset of block. Epidural opiates and benzodiazepines are well-known adjuvants. However, they are associated with side effects of respiratory depression, nausea, vomiting, pruritus, urinary retention). The alpha-2 receptor agonist is also assuming importance as an adjuvant. Indeed Clonidine, the prototype drug of this class is one of the most attractive adjuvant agents. It was the work of Schmitt et al who demonstrated the profound analgesic activity of intracerebroventricularly administered alpha sympathomimetic compounds and set the stage for the use of alpha-2 adrenergic agonist in the epidural and subarachnoid spaces. ${ }^{[1]}$ The use of centrally administered alpha-adrenergic agonist, Clonidine, has recently been buoyed by the search for an effective alternative and or adjuvant to central opiate therapy because of the absence of the side effects associated with that form of therapy. Clonidine reduces the local anaesthetic requirement and provides more stable cardiovascular course. It decreases postoperative oxygen consumption and adrenergic stress without respiratory depression. It reduces sympathetic response and accelerates onset of action thus reducing dose of local anaesthetic required.

Calcium channel conductance is required for the nervous system to signal a painful situation. Disruption of calcium influx into the cells interferes with normal sensory processing and contributes to antinociception. ${ }^{[2]}$ There is considerable evidence that excitatory amino acids and neuropeptides are involved in nociceptive transmission in the dorsal horn of the spinal cord. ${ }^{[3,4]}$ The actions of excitatory 
amino acids are mediated by the N-methyl-D- aspartate (NMDA) receptors and non-NMDA receptors. Activation of NMDA receptors leads to calcium entry into the cells and initiates a series of central sensitization. This activation of NMDA receptors is responsible for the induction and maintenance of enhanced responses for prolonged periods of time. ${ }^{[5]}$ This central sensitization may be prevented with NMDA antagonists such as calcium channel blocker, eg. verapamil. Thus, verapamil when added to ropivacaine, would improve analgesic quality and reduce postoperative analgesic consumption. A study by Huhn Choe et al. revealed the use of Bupivacaine and verapamil in epidural anesthesia, maintaining postoperative analgesia and less postoperative analgesic consumption. ${ }^{[2]}$

The present study is being undertaken to assess the analgesic properties and dose-response relationship of Clonidine and verapamil in the epidural block for abdominal hysterectomy.

\section{Subjects and Methods}

The present study was prospective, randomized, controlled and carried out in the Department of Anaesthesiology in a tertiary care medical institute. After getting permission from the institutional ethical committee, patients physical status ASA classes I and II were admitted for abdominal hysterectomy. The present study was conducted on a series of ninety patients with thirty patients in three groups undergoing abdominal hysterectomy.

The patients were divided into three groups randomly as Group 1-patient were given plain ropivacaine $(0.75 \%)$ in the dose of $20 \mathrm{ml}$, Group II $-0.75 \%$ ropivacaine $20 \mathrm{ml}$ with verapamil in the dose of $2.5 \mathrm{ml}$, Group III $-0.75 \%$ ropivacaine $20 \mathrm{ml}$ with Clonidine in the dose of $1 \mathrm{mcg} / \mathrm{kg}$ body weight. Patients of extremes of age (<20yrs \& >60yrs), ASA classes III and IV patients, patients on beta-blockers, with renal insufficiency, with cardiovascular disease \& hemodynamic instability, with bleeding diathesis and with known hypersensitivity to Clonidine and verapamil or components of the product and local anaesthetic were excluded. Each patient was re-examined thoroughly before the application of the epidural block. Heart rate (HR), Blood pressure (BP), Sp02, ECG was obtained using a continuous monitoring device. After establishing an IV line with 18gauge IV cannula, each patient was given Ringer lactate as intravenous fluid. L3-L4 interspace was palpated and 2-4 ml of ropivacaine was infiltrated over the puncture site after sterilizing and draping the site of injection. The epidural puncture was done under a full aseptic condition in L3-L4 space by Touhy's needle. Space was identified by loss of resistance (LOR) technique using LOR syringe. After negative aspiration of blood and cerebrospinal fluid, $2 \mathrm{ml}$ of $0.75 \%$ ropivacaine was injected as a test dose. The patient was observed for 5 mins to exclude subarachnoid injection as suggested by an inability to move the feet or presence of paraesthesia and tachycardia due to inadvertent intravenous injection. After $5 \mathrm{mins}, 20 \mathrm{ml}$ of ropivacaine $(0.75 \%)$ was injected in group I patient. In group II a premixed solution of $20 \mathrm{ml}$ of ropivacaine $(0.75 \%)$ and verapamil $2.5 \mathrm{mg}$ was injected, in group III a premixed solution of ropivacaine $(0.75 \%)$ and Clonidine in the dose of $1 \mathrm{mcg} / \mathrm{kg}$ body weight was given. After the application of epidural injection, patients were assessed for onset, degree, level, duration of sensory and motor block, duration of complete analgesia and postoperative analgesia, rescue analgesic requirement, sedation score and adverse effects. Modified Bromage scale was used for assessment of motor block.

Bromage scale: Grade 0- Free movement of thighs, legs and feet, Grade 1- Just able to move knees, with free movement of feet, Grade 2- Unable to move knee with free movement of knee, Grade 3- Unable to move legs or feet

Ramsay sedation score: 1-Patient anxious and agitated or restless or both 2-Patient cooperative, oriented and tranquil 3 -Patient responds to command only 4-Brisk response 5Sluggish response 6-No-response.

HR, BP, Sp02 and ECG were observed at preoperative, after epidural injection of drug, at 5 mins, 10 mins, 20 mins, 30 mins, 40 mins, 50 mins, 60 mins and at the completion of surgery. The patient was shifted to the recovery room attached to the operation theatre and HR, BP, Sp02, pain score was recorded. Postoperative analgesia was assessed by VAS which is calculated by analgesia on demand. The analgesia on demand was given and time noted. The total duration of analgesia was recorded. Complications such as nausea, vomiting, respiratory depression, hypotension, bradycardia, shivering were observed for during the period of observation and were treated appropriately.

SPSS 20.0 (SPSS Inc., Chicago, IL, USA) was used for statistical analysis. $\mathrm{P}<0.05$ was considered statistically significant.The result obtained from the three groups were compared using simple statistical methods. The unpaired ' $t$ 'test was used to compare between two groups and ANOVA among the three groups.

\section{Results}

The present study was conducted on a series of ninety patients undergoing abdominal hysterectomy. Demographically there was no significant difference found in respect of age, weight, height and mean duration of surgery. In all three groups, there was a statistically insignificant decrease in BP found just after the block. In group I and II, a significant $(\mathrm{p}<0.05)$ decrease in B.P. was found $20 \mathrm{mins}$ after the block till 50 mins. In group III, there was a statistically significant $(\mathrm{P}<0.05)$ decrease in B.P. was found 10 mins after the block and remained low till end of surgery, after which it reached the baseline value. In all the groups, there was an insignificant decrease in HR just after the block. In group, I, at 30 mins significant $(\mathrm{p}<0.05)$ decrease was observed till 40 mins. In group II, a significant $(\mathrm{p}<0.05)$ decrease was observed at 20 mins till 50 mins. In group III there was a significant $(\mathrm{p}<0.05)$ decrease in HR after 20 mins of injection, which was continued till end of surgery. [Table 1]

When groups I and II were compared statistically, the onset of sensory and motor block was found to be insignificant $(p>0.05)$. The onset of sensory and motor block was early in group III in comparison to a group I and II and was statistically significant $(\mathrm{p}<0.05)$. Between Group I and II, the duration of sensory block was found to be insignificant $(p>0.05)$. The duration of sensory block in group III was more in comparison to groups I and II and was found to be statistically significant $(\mathrm{p}<0.05)$. When groups I and II were 
compared, the duration of motor block was statistically insignificant $(p>0.05)$. On comparison between group II and III, the duration of motor block in group III was more than group II and found to be statistically significant $(p<0.05)$. Comparison between group I and III, duration of motor block in group III was more and found to be statistically significant $(\mathrm{p}<0.05)$. The mean duration of analgesia in group I was $184.03+5.20$ mins, in group II was $300.46+5.80$ mins and groups III was $538+12.80$ mins. When compared with group I, there was significant prolongation of analgesia in group II and group III $(\mathrm{p}<0.05)$. On comparison of group II and III, it was found that duration was significantly high in group III than group II $(\mathrm{p}<0.01)$. When compared with group I, there was statistically highly significant $(p<0.01)$ prolongation of analgesia in group II \& III. [Table 2]

The majority of patients had a Grade 2 blockade, according to Bromage Scale [Table 3]. The mean level of a block in all groups was T8. Only three cases block at T6 level in group III while both groups I and II have one case at T6 level [Table 4]. On sedation score, the majority of patients were of grade II. Only 12 patients out of 30 in group III were of sedation score 3 [Table 5]. Incidence of hypotension, bradycardia and nausea were more in group III, less in group I and intermediate in group II. [Table 6]

Table 1: Hemodynamics changes among groups [systolic blood pressure (SBP) and diastolic blood pressure (DBP) in mmHg]

\begin{tabular}{|c|c|c|c|c|c|c|c|c|c|}
\hline & SBP & SBP & SBP & DBP & DBP & DBP & HR & HR & HR \\
\hline Preop & $121.73+9.03$ & $121.15+9.34$ & $117.86+6.9$ & $77.37+5.53$ & $78.13+6.07$ & $\begin{array}{l}78.53+ \\
3.14\end{array}$ & $80.0+5.9$ & $\begin{array}{l}89.26+ \\
6.93\end{array}$ & $87.66+6.51$ \\
\hline $\begin{array}{l}\text { Just after } \\
\text { block }\end{array}$ & $124.66+8.31$ & $123.33+8.64$ & $119.06+4.9$ & $80.8+4.68$ & $80.40+5.41$ & $73.66+6.7$ & $\begin{array}{l}82.06+ \\
4.41\end{array}$ & $\begin{array}{l}91.23+ \\
5.69\end{array}$ & $90.06+5.19$ \\
\hline 5 Min & $120.46+6.36$ & $119.60+7.32$ & $117.42+6.12$ & $76.06+3.8$ & $76.53+4.39$ & $\begin{array}{l}69.06+ \\
5.52\end{array}$ & $\begin{array}{l}83.33+ \\
4.37\end{array}$ & $\begin{array}{l}92.00+ \\
6.36\end{array}$ & $89.60+5.64$ \\
\hline 20 Min & $110.33+3.6$ & $109.86+5.3$ & $106.60+4.9$ & $65.93+5.76$ & $70.2+6.83$ & $\begin{array}{l}63.26+ \\
6.15\end{array}$ & $\begin{array}{l}74.13+ \\
5.32\end{array}$ & $\begin{array}{l}77.66+ \\
8.38\end{array}$ & $78.26+7.54$ \\
\hline $30 \mathrm{Min}$ & $106.06+5.44$ & $105+5.69$ & $102.80+6.38$ & $62.21+4.68$ & $64.60+6.40$ & $\begin{array}{l}62.33+ \\
7.77\end{array}$ & $\begin{array}{l}71.86+ \\
4.48\end{array}$ & $\begin{array}{l}74.13+ \\
8.46\end{array}$ & $71.2+8.76$ \\
\hline 40 Min & $102.60+5.44$ & $103.86+8.5$ & $101.20+6.44$ & $66.33+8.4$ & $60.33+7.12$ & $\begin{array}{l}62.73+ \\
7.53\end{array}$ & $\begin{array}{l}67.93+ \\
5.57\end{array}$ & $75.4+8.07$ & $76.8+8.71$ \\
\hline
\end{tabular}

Table 2: Sensory and motor block in different groups (in min)

\begin{tabular}{|l|l|l|l|l|l|l|}
\hline Groups & $\begin{array}{l}\text { Onset of } \\
\text { sensory block }\end{array}$ & $\begin{array}{l}\text { Onset of } \\
\text { motor block }\end{array}$ & $\begin{array}{l}\text { Duration of } \\
\text { Sensory Block }\end{array}$ & $\begin{array}{l}\text { Duration of Motor } \\
\text { block }\end{array}$ & $\begin{array}{l}\text { Duration of } \\
\text { Complete Analgesia }\end{array}$ & $\begin{array}{l}\text { Duration of Post } \\
\text { Operative Analgesia }\end{array}$ \\
\hline GROUP I & $16.66+2.20$ & $20.31+2.70$ & $165.41+4.17$ & $101.53+3.61$ & $184.03+5.20$ & $19.96+6.98$ \\
\hline GROUP II & $16.80+2.00$ & $19.60+3.18$ & $181+4.88$ & $109.10+4.00$ & $300.46+5.80$ & $119.06+7.08$ \\
\hline GROUP III & $13.61+2.04$ & $17.38+1.96$ & $247.46+5.28$ & $162.80+5.22$ & $538+12.80$ & $288.43+8.27$ \\
\hline
\end{tabular}

Table 3: Distribution of patients according to Bromage scale

\begin{tabular}{|c|c|c|c|c|c|c|c|}
\hline \multicolumn{2}{|c|}{ Level (thoracic spinal segment) } & \multicolumn{2}{|c|}{ Group I } & \multicolumn{2}{|c|}{ Group II } & \multicolumn{2}{|c|}{ Group III } \\
\hline & & No. & $\%$ & No. & $\%$ & No. & $\%$ \\
\hline 0 & Free movement of thigh, leg feet & 3 & 10 & 3 & 10 & 1 & 3.33 \\
\hline 1 & Just able to move knee free movement of feet & 10 & 33.33 & 9 & 30 & 7 & 23.33 \\
\hline 2 & Unable to move knee with free movement of feet & 17 & 56.66 & 18 & 60 & 22 & 73.33 \\
\hline 3 & Unable to move leg or feet & 0 & 0 & 0 & 0 & 0 & 0 \\
\hline
\end{tabular}

Table 4: Distribution of patients according to level of block

\begin{tabular}{|l|l|l|l|l|l|l|}
\hline \multirow{2}{*}{ Level (thoracic spinal segment) } & Group I & Group II & Group II \\
\cline { 2 - 8 } & No. & \% & No. & \% & No. & \% \\
\hline $\mathrm{T}_{6}$ & 1 & 3.33 & 1 & 3.33 & 3 \\
\hline $\mathrm{T}_{7}$ & 8 & 26.66 & 9 & 30.0 & 8 \\
\hline $\mathrm{T}_{8}$ & 9 & 30 & 10 & 33.33 & 26.66 \\
\hline $\mathrm{T}_{9}$ & 7 & 23.33 & 6 & 20.0 & 4 \\
\hline $\mathrm{T}_{10}$ & 5 & 16.66 & 4 & 13.33 & 3 \\
\hline
\end{tabular}

Table 5: Distribution of patients according to sedation score

\begin{tabular}{|l|l|l|l|l|l|l|}
\hline \multirow{2}{*}{ Sedation Score } & Group I & Group II & Group II \\
\cline { 2 - 7 } & No. & \% & No. & \% & No. & \% \\
\hline 1 & 0 & 0 & 0 & 0 & 0 \\
\hline 2 & 26 & 86.66 & 25 & 83.33 & 18 \\
\hline 3 & 4 & 13.33 & 5 & 16.66 & 12 \\
\hline 4 & 0 & 0 & 0 & 0 & 40 & 0 \\
\hline 5 & 0 & 0 & 0 & 0 & 0 & 0 \\
\hline 6 & 0 & 0 & 0 & 0 & 0 & 0 \\
\hline
\end{tabular}


Table 6: Adverse effects among the groups

\begin{tabular}{|l|l|l|l|l|l|l|l|l|l|l|}
\hline Group & Nausea & \multicolumn{2}{l|}{ Bradycardia } & \multicolumn{2}{l|}{ Shivering } & Hypotension \\
\hline & No. & $\mathbf{\%}$ & No. & $\mathbf{\%}$ & No. & \% & No. & \% & No. & \% \\
\hline Group I & 3 & 10 & 0 & 0 & 3 & 10 & 4 & 13.33 & 3 \\
\hline Group II & 5 & 16.6 & 0 & 0 & 5 & 16.67 & 3 & 10 & 5 \\
\hline Group III & 7 & 23.33 & 0 & 0 & 7 & 23.33 & 3 & 10.33 & 7 \\
\hline
\end{tabular}

\section{Discussion}

Adjuvants are added to local epidural anesthetics in order to improve the quality, duration and degree of postoperative analgesia. Opioids, neostigmine, ketamine, Clonidine, dexmedetomidine and recently verapamil has tried in varying results. Clonidine induces antinociception by activating the descending noradrenergic inhibitory system by inhibiting synaptic transmission within the dorsal horn of the spinal cord via activation of spinal cholinergic neurons and by releasing epidural opioids. The use of calcium channel blocker verapamil as an adjuvant by Huhn Choe et al demonstrated its analgesic activity and prolongation of postoperative analgesia. ${ }^{[2]}$ Calcium channel conductance is required for the nervous system to signal a painful situation. Disruption of calcium ion movement interferes with sensory processing and contributes to antinociception. Disruption of calcium influx into the cells interferes with normal sensory processing and contributes to antinociception. Very few studies have done on verapamil, so there is a paucity of literature available on verapamil. We concluded in our study that verapamil does not affect the onset of ropivacaine induced sensory block, but Clonidine does. Verapamil has been shown not to affect the onset of sensory block. There is no evidence suggesting that verapamil, in any way affects the onset of sensory block. Klimscha et al. have observed an early block when Clonidine in a dose of $1 \mathrm{mcg} / \mathrm{kg}$ mixed with local anesthetic's. ${ }^{[6]}$ Above finding are in agreement with those found in the present study and can be explained by the fact that Clonidine acts synergistically with local anesthetics because of its action of the opening of potassium channels.

Ropivacaine produces less intense motor blockade and neither verapamil nor Clonidine had potentiated the degree of motor blockade. A previous study showed that epidural Clonidine provided effective intraoperative and postoperative analgesia. ${ }^{[7]}$ During the present study it was noted that although there was a significant enhancement in the onset of a motor block but the degree remained unchanged.

The number of patients (5) with T6 level of the blockade was highest in group III. This can also be explained on the basis of the synergistic effect of Clonidine with local anesthetics. Similar results were also reported by a previous study that concluded that Clonidine when combined with bupivacaine, produces a cephalad spread of block. ${ }^{[8]}$ None of the literature published so far had documented any effect of verapamil over the highest level of block. Neimi et al, concluded that extramurally Clonidine provides better hemodynamics and postoperative analgesia in patients undergoing knee arthroscopy. ${ }^{[9]}$ Larsen et al. concluded that intrathecal Clonidine prolongs the effect of local anesthetics. ${ }^{[10]}$ Although Clonidine might have a vasoconstrictive effect in large concentrations, the role of vasoconstriction in prolonging sensory block seems to be minor, even in usual clinical doses. In contrast, intrathecal Clonidine combined with local anesthetic, significantly potentiates the intensity \& duration of motor blockade. The explanation for this could be that a-2 adrenoreceptor agonists induce a cellular modification in the ventral horn of the spinal cord and facilitate the local anesthetic action. Similar findings were reported by, Bonnet $\mathrm{F}$ et al who concluded prolongation of motor block by Clonidine. ${ }^{[11]}$ We concluded that both verapamil and Clonidine produced a marked increase in postoperative analgesia. Addition of clonidine increase the postoperative analgesia. The findings of this study were similar to the findings of Petit J. et al, who evaluated morphine and clonidine administration epidurally for postoperative analgesia. ${ }^{[12]}$ A Similar duration of analgesia was reported when Clonidine with and without fentanyl was used for postoperative analgesia. ${ }^{[13,14]}$

Epidural verapamil decreases postoperative pain, possibly by interfering with normal sensory processing and by preventing the establishment of central sensitization. The above finding was in acceptance with Choe $\mathrm{H}$ et al. who demonstrated a combination of local anesthetics with verapamil epidurally resulted in less postoperative analgesic consumption than the local anesthetic alone. ${ }^{[2]}$ Verapamil as an adjuvant with bupivacaine, could not significantly increase the level of sensory block and attenuate postoperative pain and analgesic consumption. ${ }^{[15]}$ The above findings in agreement with Bajwa et al. who used Clonidine in his study and concluded that Clonidine enhances analgesia provided by traditional analgesics. ${ }^{[16]}$

This finding of study regarding HR was similar to the finding of Thomas et al. who used epidural Clonidine in patients undergoing cesarean section and concluded that epidural provides additional analgesia with preservation of normal HR, which he called as hemodynamic stability. ${ }^{[17]}$ The report of De Kock et al. who used epidural Clonidine as a sole analgesic agent during and after abdominal surgery also corresponds to our study. ${ }^{[18]}$ Klimscha et al. had evaluated hemodynamic and analgesic effects of Clonidine added to a continuous epidural and spinal blocks and reported a decrease in both systolic and diastolic BP and HR. ${ }^{[6]}$

Maximum cases of bradycardia were present in group III. ${ }^{[7]}$ In group II patients have bradycardia. ${ }^{[5]}$ The findings were also concluded by Bonnet $\mathrm{F}$ et al who studied postoperative analgesia of Clonidine. ${ }^{[19]}$ The highest incidence of hypotension was observed in group III, or Clonidine increases the incidence of intraoperative hypotension and bradycardia. A similar result was reported by Eisenach et a, ${ }^{[20]}$ Klimscha et al. ${ }^{[6]}$ Most of the cases of hypotension responded to inj. Ephedrine (6mg) and few cases responded to fluid therapy.

\section{Conclusion}

Verapamil in the dose of $2.5 \mathrm{mg}$ does not enhance the onset, duration of the sensory and motor block, though Clonidine in the dose of $1 \mathrm{mcg} / \mathrm{kg}$ enhances the onset of sensory block. Hemodynamically both verapamil and Clonidine are safe. 
Clonidine in the dose of $1 \mathrm{mcg} / \mathrm{kg}$ attenuates the rise in heart rate and maintains the $\mathrm{BP}$ throughout the course of the perioperative period. The duration of postoperative analgesia with verapamil was more and as compared to Clonidine, it was much higher.

\section{References}

1. Schmitt H, Douarec JCL, Petillot N. Antinociceptive effects of some alpha sympathomimetic drugs. Neuropharmacology.1974; 289-294.

2. Choe H, Kim JS, Ko SH, Kim DC, Han YJ, Song HS, Epidural verapamil reduces analgesic consumption after lower abdominal surgery. Ana Analg.1998;12:786-90.

3. Besson JM, Chaouch A. Peripheral and spinal mechanism of nociception. Physio Rev. 1987; 67:186-189.

4. Dickenson AH. Spinal cord pharmacology of pain, Br.J.Aneasthesia.1995;2:193-200.

5. Pockett S. Spinal cord spasticity and chronic pain. Anaesth Analg 1995;1:173-179.

6. Klimscha W, Chiari A, Krafft P, Plattner O, Taslimi R, Mayer $\mathrm{N}$ et al. Hemodynamic and analgesic effects of Clonidine added repetitively to continuous epidural and spinal blocks. Anaesthesia \& Analgesia 1995;2: 322-7.

7. Abd-Elsayed AA, Guirguis M, DeWood MS, Zaky SS. A Double-Blind Randomized Controlled Trial Comparing Epidural Clonidine vs Bupivacaine for Pain Control During and After Lower Abdominal Surgery. The Ochsner Journal. 2015:133-142.

8. Dobrydnjov I, Axelsson K, Thörn SE, Matthiesen P, Klockhoff $\mathrm{H}$, Holmström B et al. Clonidine combined with small dose bupivacain during spinal anaesthesia for inguinal herniorraphy: A randomized double blind study. Anaesth Analg :2003:1496-503

9. Neimi L. Effect of intrathecal Clonidine on duration of bupivacain spinal anaesthesia, hemodyanamics, posts operative analgesia in patients undergoing knee arthroscopy. Acta. Anaesth. Scand .1994:724-8
10. Larsen B, Dorscheid E, Macher- Hanselmann E,Buch U: Does intrathecal Clonidine prolongs the effect of spinal anaesthesia with hyperbaric mepivacain. A randomized double blind study. Anaesthesist.1998;47:741- 6.

11. Bonnet F, Diallo A, Saada M, Belon M, Guilbaud M, Boico O. Prevention of tourniquet pain by spinal isobaric bupivacain with Clonidine. Br. J Anaesthesia, 1989:93-96.

12. Petit J, Oksenhendler G, Colas G. Comparison of the effects of morphine, Clonidine and a combination of morphine and Clonidine administered epidurally for postoperative analgesia. Anaesthesiology.1989;5:647-452.

13. Peach, Pavy MJ, Orlikowsky TJ, Lim CE, Evans WSF. Postoperative epidural infusion: a randomized, double-blind, dose finding trial of Clonidine in combination with bupivacain and fentanyl. Anaesthesia \& Analgesia.1997;22:1323-8.

14. Singh RB, Prabhakae R, Dubey RK, Singh TB. Addition Of Clonidine Reduce Dose Of Fentanyl And Ropivacaine In Epidural Anaesthesia. Indian Journal of Clinical Anaesthesia. 2014,31-36.

15. Tabaeizavareh MH, Omranifard M, Moalemi A. The effect of verapamil as an adjuvant agent with local anesthetic on sensory block level, hemodynamic and postoperative pain. Pak J Med Sci .2012; 259-262.

16. Bajwa SJ. Kaur J, Bajwa SK, Bakshi G, Singh K, Panda A. caudal ropivacain with Clonidine: A better post operative approach. Indian J.Anaesth.2010;226-30.

17. Vetter TR, Carvallo D, Johnson JL, Mazurek MS, Presson RG. A Comparison of single-Dose Caudal Clonidine, Morphine, or Hydromorphone combined with Ropivacain in Pediatric Patients Undergiong Ureteral Reimplantation. Aneasth. Analg. 2007;1356-63.

18. De-Kock M, Gautier P, Pavlopoulou A, Jonniaux M, Lavand'homme P. Epidural Clonidine used as the sole Analgesic agent during and after abdominal surgery: A dose response study. Anaesthesiology: 1999;2285-89.

19. Bonnet F, Boico O, Rostaing S, Loriferne JF, Saada M. Clonidine induced analgesia in post operative patients. Epidural verses intramuscular administration Anaesthesiology. 1990;3:423-427.

Copyright: ( ) the author(s), 2020. It is an open-access article distributed under the terms of the Creative Commons Attribution License (CC BY 4.0), which permits authors to retain ownership of the copyright for their content, and allow anyone to download, reuse, reprint, modify, distribute and/or copy the content as long as the original authors and source are cited.

How to cite this article: Kumar S, Tripathi M, Malviya D, Rai S, Kumar S, Giri MK. Clinical Comparison of Epidural Clonidine and Verapamil with Ropivacaine in Abdominal Hysterectomy; a Prospective, Randomized, Controlled Study. Acad. Anesthesiol. Int. 2020;5(1):9195.

DOI: dx.doi.org/10.21276/aan.2020.5.1.18

Source of Support: Nil, Conflict of Interest: None declared. 